\title{
Article \\ Effect of Humidity and Temperature on the Impedances and Voltage of Al/Gr-Jelly/Cu-Rubber Composite-Based Flexible Electrochemical Sensors
}

\author{
Muhammad Tariq Saeed Chani ${ }^{1,2, *}$, Khasan S. Karimov ${ }^{3,4}$, Esraa M. Bakhsh ${ }^{2}$ and Mohammed M. Rahman ${ }^{1,2} \mathbb{E}$ \\ 1 Center of Excellence for Advanced Materials Research, King Abdulaziz University, P.O. Box 80203, \\ Jeddah 21589, Saudi Arabia; mmrahman@kau.edu.sa \\ 2 Chemistry Department, Faculty of Science, King Abdulaziz University, P.O. Box 80203, \\ Jeddah 21589, Saudi Arabia; tariqchani1@gmail.com \\ 3 Ghulam Ishaq Khan Institute of Engineering Sciences and Technology, Topi 23640, Pakistan; \\ khasan@giki.edu.pk \\ 4 Center for Innovative Development of Science and Technologies, Academy of Sciences, Rudaki Ave., 33, \\ Dushanbe 734025, Tajikistan \\ * Correspondence: mtmohamad@kau.edu.sa; Tel.: +966-26-95229
}

check for updates

Citation: Chani, M.T.S.; Karimov, K.S.; Bakhsh, E.M.; Rahman, M.M. Effect of Humidity and Temperature on the Impedances and Voltage of $\mathrm{Al} / \mathrm{Gr}$-Jelly/Cu-Rubber Composite-Based Flexible Electrochemical Sensors. Gels 2022, 8 , 73. https://doi.org/10.3390/ gels8020073

Academic Editor: Dirk Kuckling

Received: 7 December 2021

Accepted: 12 January 2022

Published: 24 January 2022

Publisher's Note: MDPI stays neutral with regard to jurisdictional claims in published maps and institutional affiliations.

Copyright: (C) 2022 by the authors. Licensee MDPI, Basel, Switzerland. This article is an open access article distributed under the terms and conditions of the Creative Commons Attribution (CC BY) license (https:// creativecommons.org/licenses/by/ $4.0 /)$.

\begin{abstract}
Here we present the fabrication of graphene and jelly (superabsorbent polymer) electrolyte composite-based shockproof flexible electrochemical sensors (Al/Gr-Jelly/Cu) and their properties under the effect of humidity and temperature. A layer of graphene mixed in jelly electrolyte was drop-casted onto porous rubber substrates between preliminary fixed aluminum (Al) and copper $\mathrm{Cu}$ electrodes followed by rubbing-in. It was observed that the graphene and jelly mixture was mechanically soft and flexible, similar to jelly. Electrically, this mixture (graphene and jelly) behaved as a flexible electrolyte. It was observed that under the effect of humidity ranging from 47 to $98 \%$, the impedances of the sensors decreased by 2.0 times on average. Under the effect of temperatures ranging from 21 to $41^{\circ} \mathrm{C}$ the impedances decreased by 2.4 times. The average temperature coefficient of impedances was equal to $-0.03{ }^{\circ} \mathrm{C}^{-1}$. The electrochemical voltage generated by the flexible jelly electrolyte sensors was also investigated. It was found that the initial open-circuit voltages were equal to $201 \mathrm{mV}$ and increased slightly, by $5-10 \%$ under the effect of humidity and temperature as well. The short-circuit currents under the effect of humidity and temperature increased by 2-3 times. The Al/Gr-Jelly/Cu electrochemical sensors may be used as prototypes for the development of the jelly electronic-based devices.
\end{abstract}

Keywords: graphene; jelly; superabsorbent polymers; graphene-jelly electrolyte composite; shockproof flexible sensor; drop casting; short-circuit currents

\section{Introduction}

As is known, humidity sensors are used in different areas of modern technology and their properties have been described in detail in the literature. Ref. [1] presented a review of materials and mechanisms for fabrication of the humidity sensors. The principles, mechanisms, and fabrication technologies of the humidity sensors were presented in Ref. [2]. The description of the thin films-based organic resistive and capacitive humidity sensors was given in Ref. [3]. The graphene oxide and PEDOT:PSS methyl red-based humidity sensors showed full range detectability and high sensitivity [4]. The synthesis and characterization of amino anthraquinone and its application as an active material in environmental sensors were described in Ref. [5].

For environmental monitoring the organic semiconductor copper phthalocyaninebased illumination and humidity sensors and their properties were described in Ref. [6]. The properties of organic-inorganic composite-based sensors were also described in Ref. [7]. A number of research articles related to humidity sensors were published by our group 
as well. The humidity sensing, microstructural, and phase properties of the cuprousoxide/orange dye composite were discussed in Ref. [8]. The graphene-orange dye solid electrolyte-based cells were characterized for humidity sensing [9]. The properties of the elastic rubber-graphene composite-based multi-functional sensors fabricated by using the rubbing-in technique were studied in Ref. [10].

During the past few years, number of graphene-based electronic devices have been designed and fabricated. The graphene-based electrochemical sensor and biosensors were fabricated and investigated by Shao et al. [11]. In Ref. [12] the wearable graphene-based infrared photodetector and temperature sensors were fabricated on a flexible polyimide substrate. A reduced graphene oxide-based flexible temperature sensor was designed and tested by Liu et al. [13]. A graphene/graphene-oxide hybrid membranes-based temperature sensor was fabricated and tested by Sun et al. [14]. The graphene-based electrochemical sensors and biosensors were designed, fabricated, and investigated as well [11].

Moreover, a number of electrochemical sensors were designed, fabricated, and investigated based on graphene as well. The electrochemical sensors fabricated on paper (where the paper was used as a scaffold to create electrodes of porous carbon nanotubes) were investigated in Ref. [15]. The conjugated polymers-based electrochemical sensors were described in Ref. [16]. Nanocomposite hydrogels for biomedical applications were described in Ref. [17].

Table 1 presents the overview of previous related work on sensor types, active materials, and fabrication techniques.

Table 1. Overview of previous related work.

\begin{tabular}{|c|c|c|c|c|}
\hline Sr. No & Sensor Type & Materials & Fabrication Technology & References \\
\hline 1 & Humidity & $\begin{array}{l}\text { PEDOT:PSS, Methyl red } \\
\text { and graphene oxide }\end{array}$ & $\begin{array}{l}\text { Ink-jet printing and spin } \\
\text { coating }\end{array}$ & {$[4]$} \\
\hline 2 & Humidity & $\begin{array}{c}\text { Chitosan- } \mathrm{CeO}_{2}-\mathrm{CdO} \\
\text { nanocomposite }\end{array}$ & Pressing & [18] \\
\hline 3 & Humidity and temperature & Amino anthraquinone & Thermal deposition & [5] \\
\hline 4 & Humidity and illumination & Copper phthalocyanine & Vacuum thermal evaporation & [6] \\
\hline 5 & Temperature and humidity & $\begin{array}{l}\text { Chitosan- }-\mathrm{CuO}-\mathrm{Fe}_{3} \mathrm{O}_{4} \\
\text { nanocomposite }\end{array}$ & Pressing & [7] \\
\hline 6 & Temperature and infrared photodetector & Graphene & Microfabrication & [12] \\
\hline 7 & Temperature sensors & Reduced graphene oxide & $\begin{array}{l}\text { Screen printing and air spray } \\
\text { coating }\end{array}$ & [13] \\
\hline 8 & Temperature & $\begin{array}{l}\text { Graphene-graphene oxide } \\
\text { hybrid films }\end{array}$ & LBL method & [14] \\
\hline 9 & Paper-based electrochemical sensors & CNTs & $\begin{array}{l}\text { Laser cutting, drop-casting, } \\
\text { and origami }\end{array}$ & [15] \\
\hline
\end{tabular}

In pursuance of our work on the sensors, in this paper we are presenting the data about the fabrication and investigation (of the electric properties) of $\mathrm{Al} / \mathrm{Gr}$-Jelly/Cu-rubber composite-based shockproof flexible solid electrochemical humidity and temperature sensors.

\section{Results and Discussions}

Figure 1a shows the graphene-jelly coating done manually using a metallic load that moved in a horizontal plane, thus pressing it against the rubber surface. The coating had a rough appearance with the pressed material oriented along one of the directions, revealing the shear forces present during the application. The coating was continuous with occasional porosity, and the pores did not seem to penetrate to the rubber substrate. The continuity of the layer revealed in the micrographs indicated that the properties of the coating were uniform within the layer and only when the layer was stretched would 
there be a change in properties such as the electrical conductivity for pressure sensing, etc. Figure $1 \mathrm{~b}$ shows the image at a high magnification. The surface roughness is more pronounced in the micrograph, which is required for the higher sensitivity of the devices.
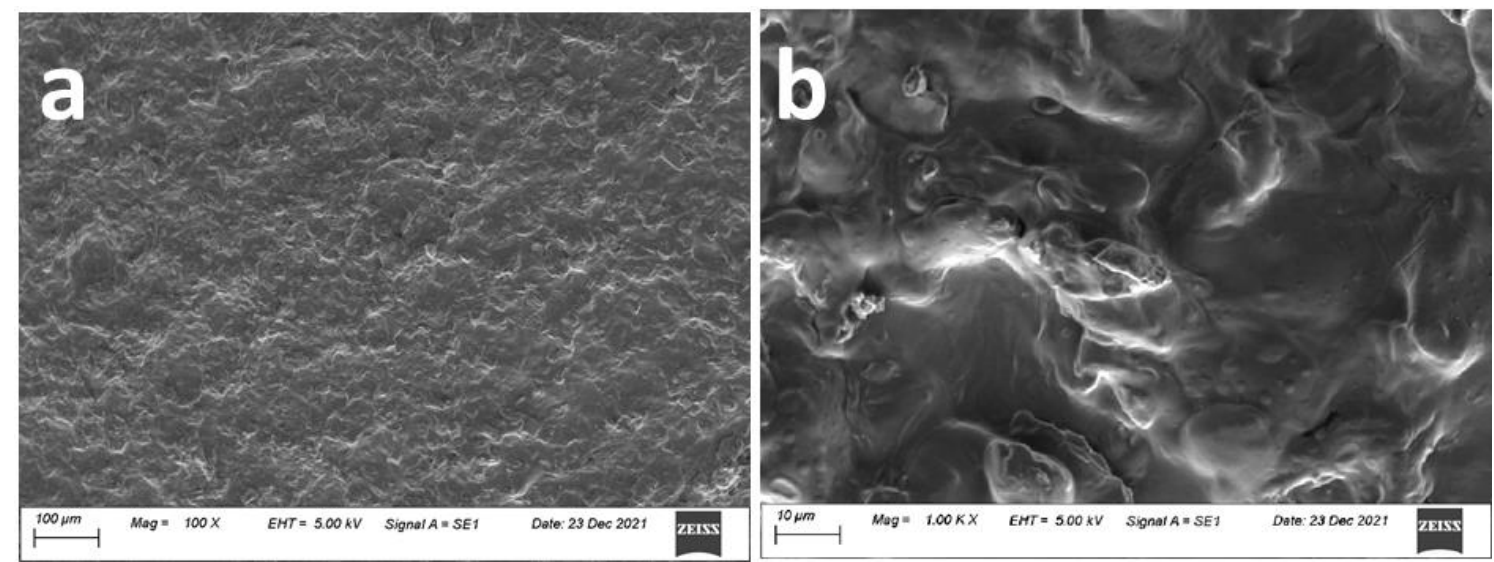

Figure 1. The SEM images showing the surface morphology of the graphene-jelly coating on the rubber substrate at (a) low and (b) high magnifications. The surface roughness is more pronounced in the micrograph.

Figure 2 shows the dependences of impedance of the Al/Gr-Jelly/Cu-rubber compositebased electrochemical sensor on the relative humidity at $22{ }^{\circ} \mathrm{C}$ (constant temperature). It was seen that on increasing humidity (from 47 to $98 \% R H$ ) the impedance decreased: in particular, 2.02 times (at $100 \mathrm{~Hz}$ ), 2.04 times (at $1 \mathrm{kHz}$ ), 2.05 times (at $10 \mathrm{kHz}$ ), 1.89 times (at $100 \mathrm{kHz}$ ), and 2.0 times (at $200 \mathrm{kHz}$ ). It was also seen that on increasing the frequency the impact of humidity on the impedance or on the sensor was approximately the same. On average, the change of the impedances was equal to 2.0. The influence of humidity on the properties of the sensor was estimated by the humidity coefficient of impedance $(\mathrm{HCI})$ :

$$
H C I=\Delta Z / \Delta R H
$$

where $\Delta Z$ is the impedance change with the change in humidity (relative) $(\Delta R H$ in $\%)$. By calculation it was found that the average $H C I$ is equal to $1.32 \mathrm{k} \Omega / \%$.

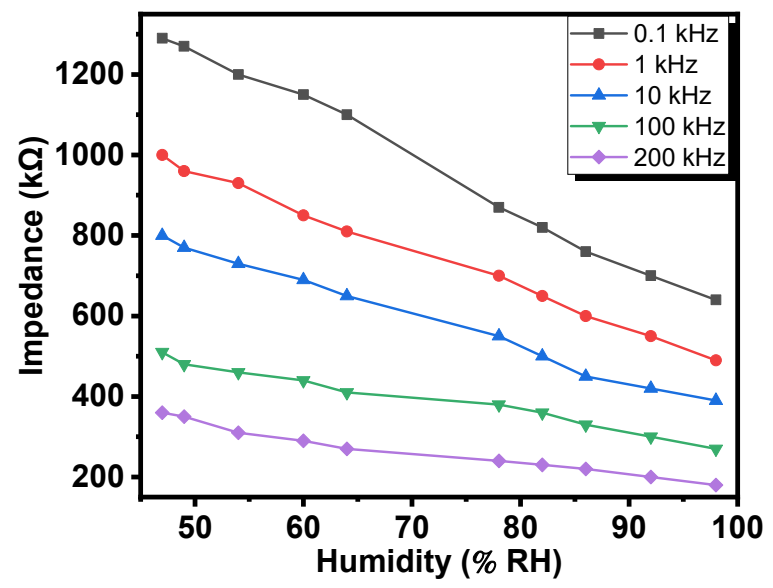

Figure 2. Dependences of the impedances of the Al/Gr-Jelly/Cu electrochemical jelly sensor on the relative humidity.

Figure 3 displays the dependence of the impedance of $\mathrm{Al} / \mathrm{Gr}$-Jelly/Cu-rubber compositebased electrochemical sensors on the temperature (in the range of 21 to $41^{\circ} \mathrm{C}$ ) at ambient humidity $(47 \% \mathrm{RH})$. The increase in temperature caused the impedance to decrease, in particular: 2.46 times $(100 \mathrm{~Hz}), 2.59$ times $(1 \mathrm{kHz}), 2.52$ times $(10 \mathrm{kHz}), 2.08$ times $(100 \mathrm{kHz})$, 
and 2.43 times $(200 \mathrm{kHz})$. It was seen that with the increase in frequency the influence of temperature on the impedance of the sensor was approximately the same; on average, the change of impedances was equal to 2 times on changing temperature from 21 to $41^{\circ} \mathrm{C}$.

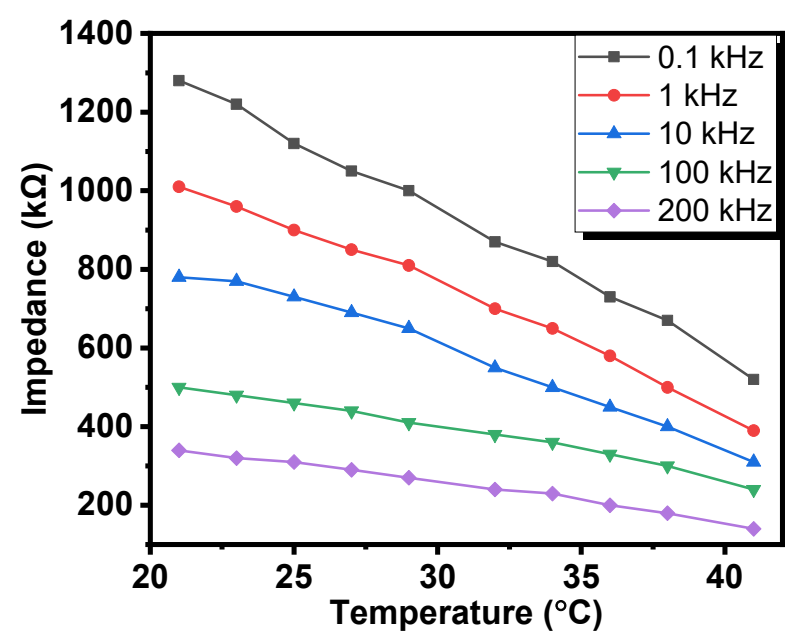

Figure 3. Dependence of the impedances of the Al/Gr-Jelly/Cu electrochemical sensors on temperature.

Analogous to the temperature coefficient of the resistance (TCR), the temperature coefficient of impedance (TCI) can also be introduced:

$$
T C I=\Delta Z / Z \Delta T \text {. }
$$

The values of the temperature coefficient of impedance $(T C I)$ were equal to $(-0.030)^{\circ} \mathrm{C}^{-1}$ for $0.1 \mathrm{kHz},(-0.031){ }^{\circ} \mathrm{C}^{-1}$ for $1 \mathrm{kHz},(-0.030){ }^{\circ} \mathrm{C}^{-1}$ for $10 \mathrm{kHz},(-0.026){ }^{\circ} \mathrm{C}^{-1}$ for $100 \mathrm{kHz}$ and $(-0.026){ }^{\circ} \mathrm{C}^{-1}$ for $200 \mathrm{kHz}$.

Comparison of these values of the temperature coefficient of impedance with the TCR of some of the metals that are used in electronics (e.g., silver (0.0038), copper (0.0039) and aluminum (0.0043)) showed that the resistance-temperature behavior of the graphene-jelly composite was similar to that of semiconductors rather than that of metals.

Figure 4 shows the impedance-frequency relationship of the Al/Gr-Jelly/Cu-rubber composite-based electrochemical sensors at a temperature of $21{ }^{\circ} \mathrm{C}$ and a humidity of $47 \% \mathrm{RH}$. It can be seen that on increasing the frequency the impedance decreased. This can be explained by the presence of "built-in" resistance and capacitance that can be shown in the sensor's equivalent circuit.

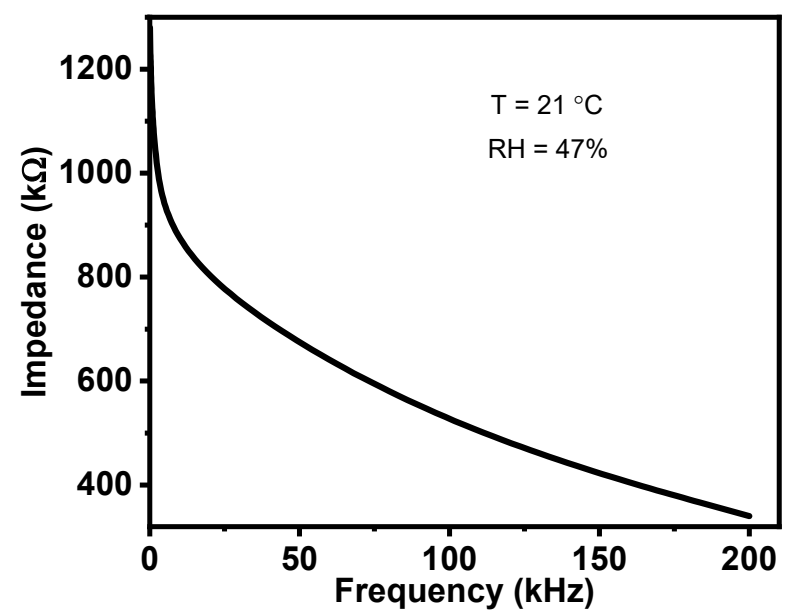

Figure 4. Dependence of the impedance of the $\mathrm{Al} / \mathrm{Gr}-\mathrm{Jelly} / \mathrm{Cu}$-rubber electrochemical sensor on frequency. 
It was found that the fabricated $\mathrm{Al} / \mathrm{Gr}-J e l l y / \mathrm{Cu}$ electrochemical sensors generated voltage. Figure 5 shows the dependences of the $V_{o c}$ (open-circuit voltage) and $I_{S C}$ (shortcircuit current) of the sensor on humidity. The $V_{o c}$ increased by $5 \%$ and $I_{S C}$ increased by 2 times on increasing the relative humidity from 47 to $98 \%$.

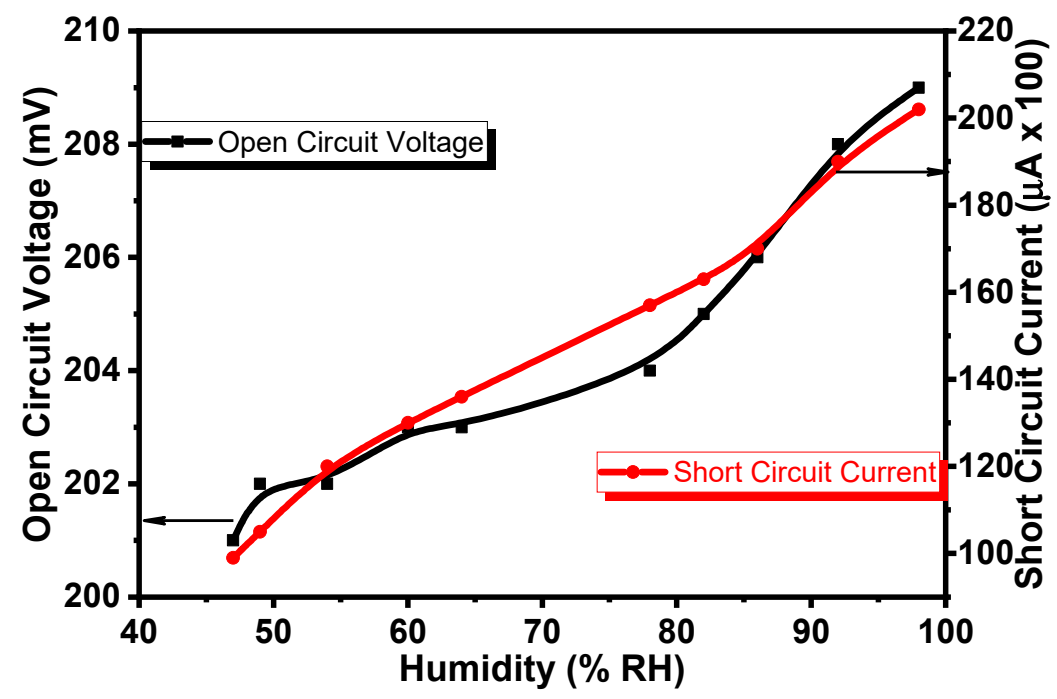

Figure 5. Dependence of the $V_{o c}$ (open-circuit voltage) and $I_{S C}$ (short-circuit current) of the Al/GrJelly/Cu electrochemical sensor on humidity.

Figure 6 shows the dependences of the $V_{o c}$ and $I_{s c}$ of the Al/Gr-Jelly/Cu electrochemical sensor on temperature. It was seen that the $V_{O C}$ and the $I_{S C}$ of the sensor depended on the temperature as well (Figure 6): on increasing the temperature from 21 to $41^{\circ} \mathrm{C}$ the $V_{o c}$ increased by $7 \%$ and the $I_{S C}$ increased by 3 times.

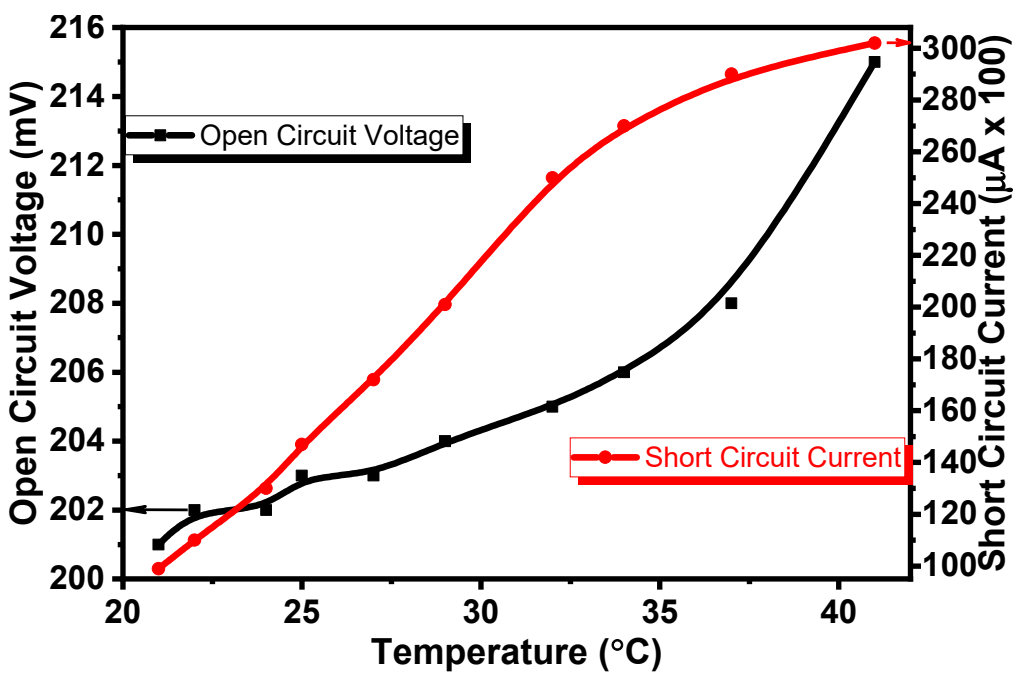

Figure 6. Dependence of $V_{o c}$ (open-circuit voltage) and the $I_{S C}$ (short-circuit current) of the Al/GrJelly/Cu electrochemical sensor on temperature.

The equivalent circuit of the $\mathrm{Al} / \mathrm{Gr}$-Jelly/ $\mathrm{Cu}$ electrochemical sensor is shown in Figure 7, which is a parallel connection of the resistance $R$ and the capacitance $C$, while the voltage source $E$ is connected in series. The fabricated electrochemical sensors have two metallic electrodes with different standard electrochemical potentials equal to $-1.66 \mathrm{~V}$ for $\mathrm{Al}$ and $+0.34 \mathrm{~V}$ for $\mathrm{Cu}$; that is why the generation of the electric voltage takes place $[19,20]$. 


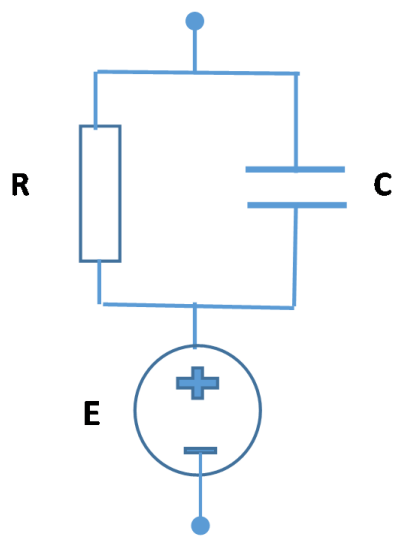

Figure 7. Simplified equivalent circuit of the $\mathrm{Al} / \mathrm{Gr}-J e l l y / \mathrm{Cu}$ electrochemical sensor.

Figure 8 shows the I-V characteristics of the Al/Gr-Jelly/Cu-rubber electrochemical sensor at a humidity of $47 \%$ and a temperature of $21^{\circ} \mathrm{C}$.

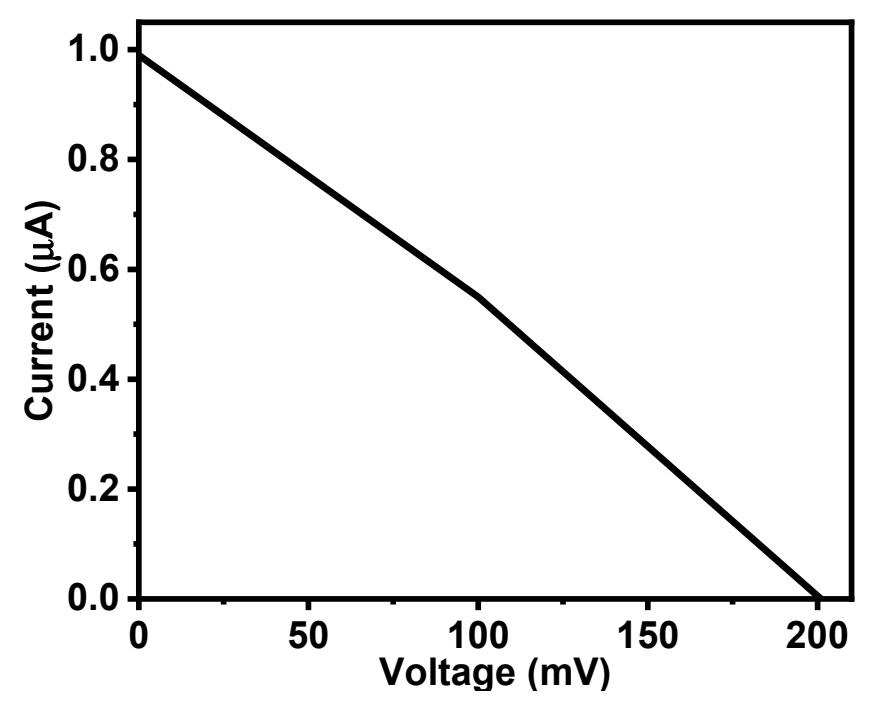

Figure 8. $\mathrm{I}-\mathrm{V}$ characteristics of the $\mathrm{Al} / \mathrm{Gr}-J e l l y / \mathrm{Cu}$ electrochemical sensors at $47 \%$ humidity and $21^{\circ} \mathrm{C}$ temperature.

The literature survey allowed disclosure of the following information concerning the investigations regarding the effect of humidity and temperature on the impedance and voltage of $\mathrm{Al} / \mathrm{Gr}$-Jelly/Cu-rubber composite-based flexible electrochemical sensors. Concerning the humidity effect on the electric properties of the materials two mechanisms may be considered. First of all, diffusion of water molecules into the material increases the dielectric permittivity. Secondly, the self-ionization of water molecules into protons $\left(\mathrm{H}^{+}\right)$ and hydroxide ions $(\mathrm{OH})$ finally results in the separation of $\left(\mathrm{H}^{+}\right)$and $\left(\mathrm{OH}^{-}\right)$(as shown in Equation (3)) and causes the concentration of charges to increase.

$$
\mathrm{H}_{2} \mathrm{O}<=>\mathrm{H}^{+}+\mathrm{OH}
$$

In Ref. [1] the mechanisms of the humidity effect on the electric properties of the polymer materials were discussed as well. Moreover, the ceramic and polymer-based sensors were also reviewed. Sensitivity, response time, stability, and the sensing mechanism were also discussed. The literature survey allowed us to disclose the information concerning the investigations of the electrochemical sensors shown in this paper.

Concerning the effect of temperature on the electric properties of the organic materials, it should be said that there were several investigations. In particular, Ref. [21] investigated 
the I-V characteristics of the graphene samples, and it was found that the current especially increased when temperature reached above $150{ }^{\circ} \mathrm{C}$.

The analysis of the data from the literature showed that the obtained results in this paper are supplementary. We hope these results will be useful, first of all for the fabrication of cheap and flexible devices, which may be especially important as a teaching aid. Secondly, these results are also important for the investigation and understanding of the physical and electrochemical properties of the flexible composites and their potential applications. In particular, the application of organic materials in applied electronic devices is very important, such as the realization of jelly electronics in vibration conditions.

\section{Conclusions}

In this paper information about the materials, fabrication technology, and the properties of environmentally friendly flexible electrochemical humidity and temperature sensors was presented. The sensor, having $\mathrm{Al}$ and $\mathrm{Cu}$ electrodes, was based on the organic material graphene and jelly composite as an active material. It was found that the sensor's impedance was sensitive to the concentration of the humidity, temperature, and frequency of the applied voltages. Moreover, the sensor's short-circuit current depended on the humidity and temperature. The sensor is a combination of three elements: resistance, capacitance, and electrochemical cells. First, the proper selection of the ingredients (graphene and jelly) and their ratio; second, the fabrication technology; and third, the structure of the sensors allowed us to realize the shockproof flexible humidity and temperature sensors. Because of the simplicity of fabrication technology these sensors can be used in practice and as a teaching aid as well. Our preliminary investigations and estimations showed that the sensors are not costly, having practically acceptable sensitivity and stability of the properties. Much graphene-related research work has shown that this organic material is environmentally friendly; no negative effect was observed by us as well. Our preliminary experiments showed that in this sensor the copper can be replaced by CNT (the work functions of both materials are close to $\sim 5 \mathrm{eV}$ ), which can make it cheaper and acceptable for utilization in practice.

\section{Experimental}

To fabricate the Al/Gr-Jelly/Cu-rubber composite-based flexible electrochemical sensor the graphene was purchased from the Sigma Aldrich (Merck KGaA, Darmstadt, Germany), while the jelly and the rubber substrates were purchased from the market. The graphene's structure and its disorders were discussed in Ref. [22]. Figure 9 shows the molecular structures of the graphene.

(a)

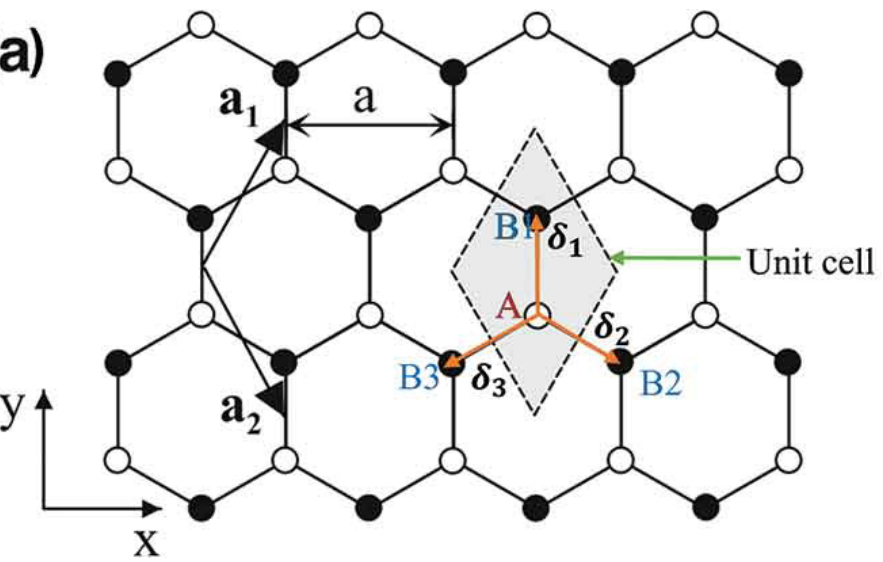

(b)

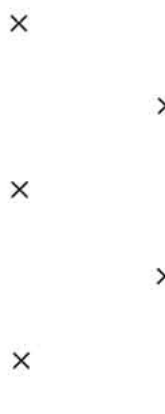

$\times$

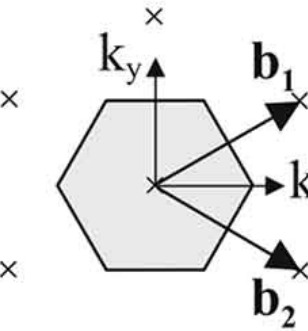

$\times$

$\times$

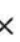

$\times$

$\times$

Figure 9. (a) Monolayer graphene (honeycomb lattice), where the carbon atoms are indicated by white (black) circles on A (B) sites, and (b) the monolayer graphene's reciprocal lattice, where the corresponding Brillouin zone is indicated by shaded hexagon. 
The gel used for these sensors is made of superabsorbent polymers such as crosslinked sodium polyacrylate, cross-linked sodium carboxymethyl cellulose, etc. This gel is inodorous, non-edible, environmentally friendly, and used for fairy crafts for kids and indoor plantations. It is commercially available with a trade name of Rainbow Crystal Clay (http: / / www.miracle-chemical.com/Products.asp?ClassID=115, accessed on 6 December 2021) (Tianhe District, Guangzhou, China). The addition of other materials such as graphene, CNTs, or orange dye makes the gel conductive or semiconductive. Moreover, it is also important that the gel should be like glue.

The humidity and temperature sensors based on graphene/transparent jelly were fabricated by the rubbing-in technique. The mixture of ingredients was deposited onto rubber substrates between the preliminary fixed $\mathrm{Al}$ and $\mathrm{Cu}$ foil electrodes. In the $\mathrm{Al} / \mathrm{Gr}$ Jelly/Cu-based sensors, the graphene and jelly adhesive composite was in the following proportion: $50 \mathrm{wt}$. \% and $50 \mathrm{wt}$. \%. The gap between two ( $\mathrm{Al}$ and $\mathrm{Cu}$ ) electrodes was kept to $1 \mathrm{~mm}$. The sizes of the rubber substrates were the following: length, width and thickness were equal to 20:10:10 $\mathrm{mm}^{3}$. Figure 10 illustrates the schematic of the front view (a) and the top view (b) of the Al/Gr-Jelly/Cu-rubber composite-based shockproof flexible electrochemical humidity and temperature sensor.

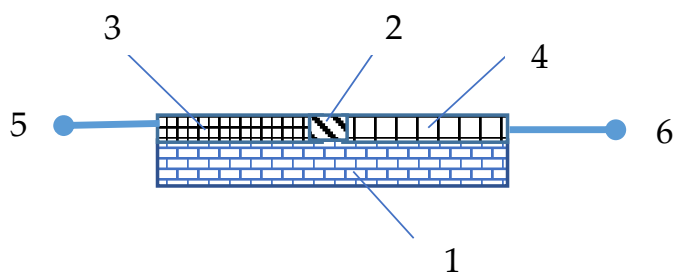

(a)

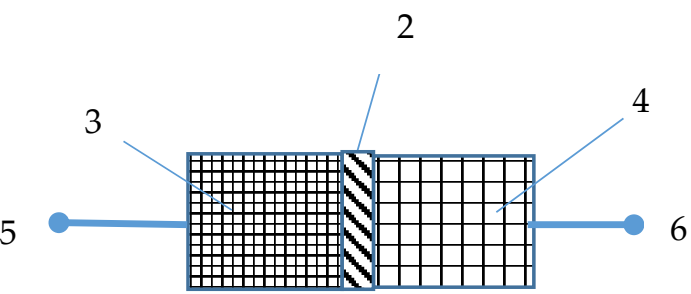

(b)

Figure 10. Schematic diagram showing the front view (a) and the top view (b) of the Al/Gr-Jelly/Curubber composite-based shockproof flexible electrochemical humidity and temperature sensors: rubber substrate (1), graphene and jelly (superabsorbent polymer) composite (2), Al electrode (3), $\mathrm{Cu}$ electrode (4), metallic terminals (5 and 6).

The micrographs were taken using an Evo-15 W filament scanning electron microscope at an accelerating voltage of $5 \mathrm{KeV}$. A secondary electrons detector was used to obtain the micrographs.

The MT 4090 (digital LCR-meter) was used for the measurement of the impedance at various frequencies ranging from $100 \mathrm{~Hz}$ to $200 \mathrm{kHz}$. For the measurements of the voltage the DT 4253 multimeter was used. Humidity and temperature were measured by the TECPEL 322. The testing was done in a special chamber with a built-in heating system.

Author Contributions: Conceptualization, M.T.S.C. and K.S.K.; methodology, M.T.S.C.; software, M.T.S.C.; validation, M.T.S.C., K.S.K. and M.M.R.; formal analysis, M.T.S.C. and E.M.B.; investigation, M.T.S.C. and M.M.R.; resources, K.S.K.; data curation, M.T.S.C. and E.M.B.; writing—original draft preparation, M.T.S.C.; writing-review and editing, K.S.K., E.M.B. and M.M.R.; visualization, K.S.K.; supervision, K.S.K.; project administration, K.S.K.; funding acquisition, M.T.S.C. All authors have read and agreed to the published version of the manuscript.

Funding: This research work was funded by Institutional Fund Projects under grant no. IFPHI-125130-2020. 
Institutional Review Board Statement: Not applicable.

Informed Consent Statement: Not applicable.

Data Availability Statement: Data will be available upon request.

Acknowledgments: This research work was funded by Institutional Fund Projects under grant no. IFPHI-125-130-2020. Therefore, the authors gratefully acknowledge technical and financial support from the Ministry of Education and King Abdulaziz University, DSR, Jeddah, Saudi Arabia.

Conflicts of Interest: The authors declare no conflict of interest.

\section{References}

1. Chen, Z.; Lu, C. Humidity sensors: A review of materials and mechanisms. Sens. Lett. 2005, 3, 274-295. [CrossRef]

2. Farahani, H.; Wagiran, R.; Hamidon, M.N. Humidity sensors principle, mechanism, and fabrication technologies: A comprehensive review. Sensors 2014, 14, 7881-7939. [CrossRef] [PubMed]

3. Najeeb, M.A.; Ahmad, Z.; Shakoor, R.A. Organic Thin-Film Capacitive and Resistive Humidity Sensors: A Focus Review. Adv. Mater. Interfaces 2018, 5, 1800969. [CrossRef]

4. Hassan, G.; Sajid, M.; Choi, C. Highly Sensitive and Full Range Detectable Humidity Sensor using PEDOT: PSS, Methyl Red and Graphene Oxide Materials. Sci. Rep. 2019, 9, 15227. [CrossRef]

5. Ali, S.; Tahir, M.; Mehboob, N.; Wahab, F.J.; Langford, S.; Said, S.R.M.; Sarker, M.; Julai, S.; Hamid Md Ali, S. Amino Anthraquinone: Synthesis, Characterization, and Its Application as an Active Material in Environmental Sensors. Materials 2020, 13, 960. [CrossRef]

6. Karimov, K.S.; Qazi, I.; Khan, T.; Draper, P.; Khalid, F.; Mahroof-Tahir, M. Humidity and illumination organic semiconductor copper phthalocyanine sensor for environmental monitoring. Environ. Monit. Assess. 2008, 141, 323-328. [CrossRef] [PubMed]

7. Chani, M.T.S. Impedimetric sensing of temperature and humidity by using organic-inorganic nanocomposites composed of chitosan and a CuO-Fe ${ }_{3} \mathrm{O}_{4}$ nanopowder. Microchim. Acta 2017, 184, 2349-2356. [CrossRef]

8. Karimov, K.S.; Saleem, M.; Iqbal, Y.; Fatima, N.; Gohar, R. Phase, microstructural analysis, and humidity-sensing properties of orange dye and cuprous-oxide composite. Appl. Phys. A 2017, 123, 1-7. [CrossRef]

9. $\quad$ Chani, M.T.S.; Karimov, K.S.; Meng, H.; Akhmedov, K.M.; Murtaza, I.; Asghar, U.; Abbass, S.Z.; Ali, R.; Asiri, A.M.; Nawaz, N. Humidity sensor based on orange dye and graphene solid electrolyte cells. Russ. J. Electrochem. 2019, 55, 1391-1396. [CrossRef]

10. Karimov, K.S.; Ahmad, Z.; Khan, M.I.; Siddiqui, K.J.; Qasuria, T.; Abbas, S.Z.; Usman, M.; Rehman, A.-U. Elastic layered rubber-graphene composite fabricated by rubbing-in technology for the multi-functional sensors. Heliyon 2019, 5, e01187. [CrossRef]

11. Shao, Y.; Wang, J.; Wu, H.; Liu, J.; Aksay, I.A.; Lin, Y. Graphene Based Electrochemical Sensors and Biosensors: A Review. Electroanalysis 2010, 22, 1027-1036. [CrossRef]

12. Sahatiya, P.; Puttapati, S.K.; Srikanth, V.V.S.S.; Badhulika, S. Graphene-based wearable temperature sensor and infrared photodetector on a flexible polyimide substrate. Flex. Print. Electron. 2016, 1, 025006. [CrossRef]

13. Liu, G.; Tan, Q.; Kou, H.; Zhang, L.; Wang, J.; Lv, W.; Dong, H.; Xiong, J. A Flexible Temperature Sensor Based on Reduced Graphene Oxide for Robot Skin Used in Internet of Things. Sensors 2018, 18, 1400. [CrossRef] [PubMed]

14. Sun, P.; Zhu, M.; Wang, K.; Zhong, M.; Wei, J.; Wu, D.; Zhu, H. Small Temperature Coefficient of Resistivity of Graphene/Graphene Oxide Hybrid Membranes. ACS Appl. Mater. Interfaces 2013, 5, 9563-9571. [CrossRef] [PubMed]

15. Valentine, C.J.; Takagishi, K.; Umezu, S.; Daly, R.; De Volder, M. Paper-Based Electrochemical Sensors Using Paper as a Scaffold to Create Porous Carbon Nanotube Electrodes. ACS Appl. Mater. Interfaces 2020, 12, 30680-30685. [CrossRef]

16. Rahman, M.A.; Kumar, P.; Park, D.-S.; Shim, Y.-B. Electrochemical Sensors Based on Organic Conjugated Polymers. Sensors 2008, 8, 118-141. [CrossRef]

17. Gaharwar, A.K.; Peppas, N.A.; Khademhosseini, A. Nanocomposite hydrogels for biomedical applications. Biotechnol. Bioeng. 2014, 111, 441-453. [CrossRef]

18. Chani, M.T.S. Fabrication and characterization of chitosan- $\mathrm{CeO}_{2}-\mathrm{CdO}$ nanocomposite based impedimetric humidity sensors. Int J. Biol. Macromol. 2022, 194, 377-383. [CrossRef]

19. Hopkins, J.; Fidanovski, K.; Lauto, A.; Mawad, D. All-Organic Semiconductors for Electrochemical Biosensors: An Overview of Recent Progress in Material Design. Front. Bioeng. Biotechnol. 2019, 7, 237. [CrossRef]

20. Khan, M.K.A.; Rahman, M.S.; Das, T.; Ahmed, M.N.; Saha, K.N.; Paul, S. Investigation on parameters performance of Zn/Cu electrodes of PKL, AVL, Tomato and Lemon juice based electrochemical cells: A comparative study. In Proceedings of the 2017 3rd International Conference on Electrical Information and Communication Technology (EICT), Khulna, Bangladesh, 7-9 December 2017; pp. 1-6.

21. Haditale, M.; Dariani, R.S.; Lemraski, E.G. Electrical behavior of graphene under temperature effect and survey of I-T curve. J. Theor. Appl. Phys. 2019, 13, 351-356. [CrossRef]

22. Yang, G.; Li, L.; Lee, W.B.; Ng, M.C. Structure of graphene and its disorders: A review. Sci. Technol. Adv. Mater. 2018, 19, 613-648. [CrossRef] [PubMed] 